\title{
Study on Wang Zhixin's National Vocal Music Works "Lady Meng Jiang"
}

\author{
Qilong Shi \\ Anshan Normal University \\ Anshan, China
}

\begin{abstract}
Wang Zhixin's national vocal music works mainly are used in the vocal music teaching in universities and colleges in China. There are only a few researches on the singing of Wang Zhixin's national vocal music works at home and abroad. Most of the researches are brief comments on very few song writings and social activities, which analyzed the works from the perspective of a composer. So far very few people give systematic and clear analysis and summary on Zhang Zhixin's national vocal music works from the angle of singing. The paper has made a detailed analysis on Wang Zhixin's National Vocal Music Works "Lady Meng Jiang" from the angle of singing, discussed the creation subject, writing techniques, harmonic progression, emotional expression and other singing characteristics, and put forward some suggestions on processing songs. The author hopes to provide some references to the majority of the singers loving national vocal music.
\end{abstract}

Keywords-Wang Zhixin; singing; national vocal music

\section{INTRODUCTION}

Wang Zhixin, national first-class composer, conductor and vocal music educator, native in Henan Leting, is good at creating national vocal music works. His works have prominent subjects and rich content, producing a wide range of influence in Chinese national vocal music field. The newly created folk songs of Mr. Wang Zhixin are based on a widely range of content. It has the national characteristics of traditional folk song overture and dramatic music language. In innovative forms of folk song, Wang Zhixin not only retains the inherent tradition singing of folk song, but also deliberately uses modern pop music to enrich the monotonous accompaniment of folk music in the process of accompaniment. "Lady Meng Jiang" is one of his representatives in the national vocal musical works. This song is given with rich emotions. It has the sentiment of sadness and the tremendous momentum. Therefore, it has a high requirement on singer's singing skills and emotion expression. The following analysis is carried out to provide some references to singers.

\section{ANALYSIS OF THE CHARACTER IN "LADY MENG JIANG"}

The story of "Lady Meng Jiang" has been spread for thousands of years. It was a beautiful but sad myth. Along the longitudinal line of the era, behind the story is the deep hidden social significance. Lady Meng Jiang was the wife of Qi Liang of Qi Chao in the spring and autumn period. She was an understanding and sensible woman. The leading character of this story is Lady Meng Jiang. She sent winter clothing to her husband thousands miles away. When she arrived, others told her that his husband had died. She cried at the Great Wall for days and nights. Her story touched the heaven and the earth. The Great Wall was collapsed. She knew her husband would never come back again, so she drowned herself in the river. This story reflected Lady Meng Jiang's sincere love to her husband. The government forced ancient people to build the Great Wall. And the work was too heavy. Ancient people associated their situations with the construction of the Great Wall ordered by the First Emperor of Qin State. This story reflected that Lady Meng Jiang was a woman against tyranny and loyal to her husband.

\section{THE CREATION BACKGROUND OF LADY MENG JIANG}

"Lady Meng Jiang”, also known as "Lady Meng Jiang Crying at the Great Wall", is a touching story. It has been widely spreads in the folk for hundreds of years. This story reflected the inner indignation and sad resentment of the oppressed people in the feudal society and praised the loyalty of Lady Meng Jiang to her husband and her missing to her husband. At the Shanhai Guan of Qinhuangdao, the later generations built a temple and erected a statue to memory her. The song of "Lady Meng Jiang" has 12 paragraphs. It tells a story of a newly married couple who suffering life and death in the period of the reign of the First Emperor of Qin State. They married for three days, and the husband was forced to leave and build the Great Wall. Lady Meng Jiang missed her husband far away, so she left home to seek her husband with innumerable trials and hardships. When she arrived at the Suzhou Hushu Guan, one governmental official stopped her. Lady Meng Jiang sang her story to the official, and the official was moved and let her go. She finally found the building site of her husband. But to her sadness, her husband had died. Lady Meng Jiang was very sad, so she cried at the Great Wall for three days and three nights. The Great Wall was collapsed. In despair Lady Meng Jiang drowned herself in the river. The new version of "Lady Meng Jiang" is the national vocal music works of Composer Wang Zhixin and Songwriter Liu Lin published in the 1980s. It was adapted according to Jiangsu Folk Song "Lady Meng Jiang". Wang Zhixin used the variation technique, which changed the squared structure and simplicity of the whole works and make the music melody more full. The emotion of the whole song becomes deeper, and is given with strong authenticity and appeal. The whole song is beautiful in melody, deep in emotion, delicate and euphemistic, 
and compact in structure. The beautiful but sad story has been spread till now. It has a great influence, for it conforms to the historical and social ideas. It praises Lady Meng Jiang. What's more, it combines music with story.

\section{THE MUSIC ONTOLOGY AND SINGING PROCESSING IN "LADY MENG JIANG"}

\section{A. Analysis of Musical Form, Melody and Lyrics}

"Lady Meng Jiang" is a large-scale multi-section musicalstructure vocal music works. The song is divided into four sections. Four different modes run through the whole song, including D Hui Qing Yue mode, D Hui Liu Sheng with Bian Gong, D Yu Qing Yue and F Hui Liu Sheng with Bian Gong. The whole song is singed at the adagio speed. The sentimental and steady rhythm euphemistically tells the feelings of Lady Meng Jiang. The whole song mainly uses the rhythm of $2 / 4$, $3 / 4$ and $4 / 4$. Singers shall pay attention to the speed of the whole song in singing. Different rhythms express different music colors. The mode conversion had laid a certain foundation for the entire works.

The first section of the song is a narrative theme. The author retained the Hui mode and its qi-cheng-zhuan-he structure of original folk songs. Starting with slightly slow melody, the plaintive and euphemistic tune recounts Lady Meng Jiang's missing to her husband. In lyrics, every family was happy in the lunar January, and husbands and wives got together. It is an obvious contrast to her situation. Her husband went out to build the Great Wall. This section is the prelude of the whole works. It also reflected Lady Meng Jiang's missing to her husband far away and her helplessness. The second section is similar with the first section. Only the rhythm becomes slower. It is the development of the first section. The melody and singing become stronger, further setting off Lady Meng Jiang's missing to her husband and her grief and indignation to the society at that time.

The third section gradually becomes plaintive and euphemistic. It changes in mode and tonality, from D Hui Liu Sheng with Bian Gong to D Yu Qing Yue. The music melody with lyrics incisively and vividly expresses her missing to her husband. From the first lunar January to the Double Ninth Festival, Lady Meng Jiang placed her missing on sewing clothes. The interlude between the third and fourth section is one of the highlights in this works. It adds column chords in the piano accompaniment. Tremolo, triplet and octuplet are performed round and round, which enhances the rendering of music and makes a good foundation for the climax of the following fourth section.

With the progress of music, the works enters into a climax in the fourth section. The song changes from slow pace to fast pace gradually. The composer used the Yaoban of compact playing and slow singing and Duoban from slow to fast in the opera music. In lyrics, snowflakes fluttered about, and it was unable to move a tiny step. It vividly describes the hard situation of Lady Meng Jiang in her journey to find her husband. At the beginning of fourth section, the rhythm changes obviously, forming a sharp contrast with previous foreshadowing. With strong emotion, the pace increases gradually. From $4 / 4,3 / 4$ to $2 / 4$, the beat decreased gradually. The 32 note goes up rapidly, pushing the emotion of the whole song to the peak. The melody also goes to the highest range. It clearly reflects the hard times and grief and indignation of Lady Meng Jiang in seeking her husband, and the darkness and tyranny of the society at that time.

\section{B. The Singing Processing}

The works of Wang Zhixin and Liu Lin, "Lady Meng Jiang", was composed in a new way of thinking and creative expression technique. It has become a widely known and catchy folk song. It gives the sad ancient folk song with new brilliance. On the basis of original folk song's melodic style and musical color, the author changed the ballad structure of original folk song with four sentences, broke the squared structure and simplicity of original song, used modern composing techniques and the expression techniques of Yaoban and Duoban in opera music, and expanded and highlighted the theme of music through several modulations. He made the simple minor folk song into a large-scale heartshocking and moving multi-section vocal music works. It not only retains the style of original folk song and is full of new meaning, so that the whole piece of music have been sublimated and expanded in the realm of art.

The first section of "Lady Meng Jiang" basically retains the original tunes of the traditional folk song. The start speed is very slow. The expression terms are plaintive and euphemistic. When the accompaniment slowly enters into, the singer needs to get into character. The singer shall carry a feeling of separation from her husband and a feeling of envy that other couples get together. Missing her husband far away, the singer sings the causes of the story. Then it shows Lady Meng Jiang's pain and her inner sadness. The singer shall ponder the meaning of lyrics, carefully weigh and express the resentment of Lady Meng Jiang in a gentle lingering and narrative way.

In the second section, the composer processed the art of original folk song. The use of segmentation notes and 16 notes make the melody flow. The story goes further. "Lady Meng Jiang looked at the Great Wall, and cried sadly". This image reflected Lady Meng Jiang's longing for her husband. In the lyrics of “我与杞良哥何日能重逢”, the composer lengthens “逢”. In singing folk music, the writing technique of extending several bars is often used, for it can amplify and extend the core of theme, and relevantly express the central meaning. The singer should sing it with a sobbing tone. The voice is on and off, while the breath is continuous. "与” shall be slightly highlighted to express Lady Meng Jiang's longing for reunion with her husband early and her grief and sadness because of little hope. 
Example 1

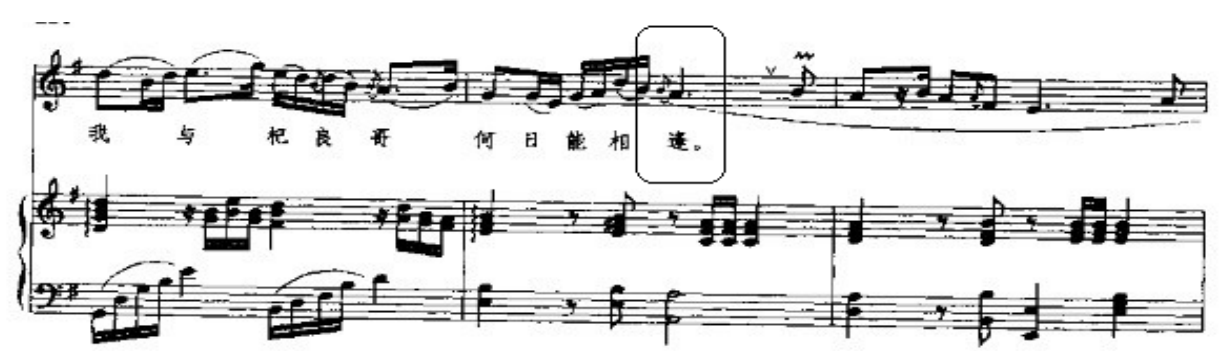

Sing in sobbing tone with on and off voice and continuous breath.

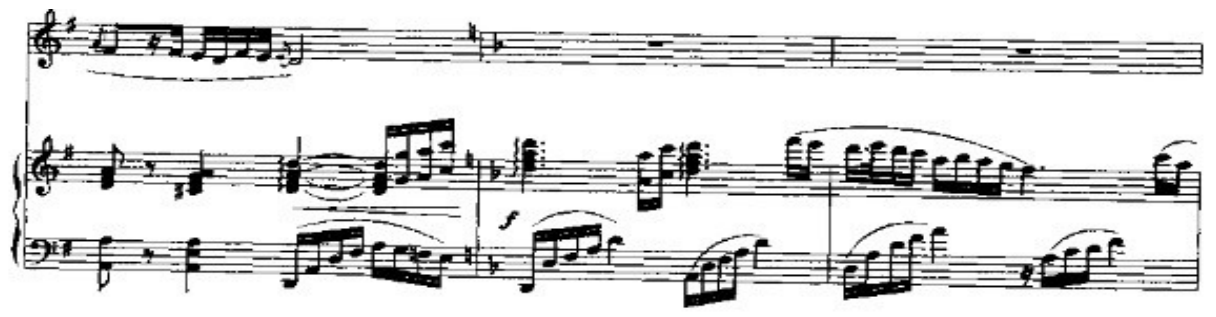

When entering the third section, the mode and tonality changes. From the interlude, it changes from $\mathrm{G}$ major mode to $\mathrm{f}$ minor mode. Due to the change of tonality, the tones also change greatly. In the development of music, it again stresses Lady Meng Jiang's eagerness to get together with her husband. This section first described that Lady Meng Jiang longed for her husband from the lunar January to the Double Ninth Festival. The emotion is revealed more directly than previous sections. With slow pace, the singer shall narrate from inner heart. The song changes from $\mathrm{Yu}$ into Hui mode. The tone sounds softer. The color contrast makes the whole melody sadder. When singing “落叶飘, 秋风凉到针针线线密密缝”, the singer shall set off the sad atmosphere fully and sing with a feeling of sobs. In singing “线是相思, 针是情啊”, the singer shall embellish “针” and make it stabbing. The singer herself sings as if she lost her husband. So, she could vividly express Lady Meng Jiang's helplessness and painful feeling because of missing her husband. In each sentence, the last word shall be expressed deliberately with true emotion, so that the works is more infectious. The speed of the next sentence shall increase slightly, and grow stronger slowly, which can bring the mood to the climax. The second sentence of “絮进寒衣伴君行” stretches the melodic line on the basis of the first sentence of “絮进寒衣伴君行”. With steady breath, the emotion is sent out from inside to outside, pushing the development of the music. It arouses audiences to taste Lady Meng Jiang's sadness, hardship and pain. The voice shall change from weak to slightly strong and then to weak, so the whole music atmosphere is pushed to another height and become more touching.

Example 2
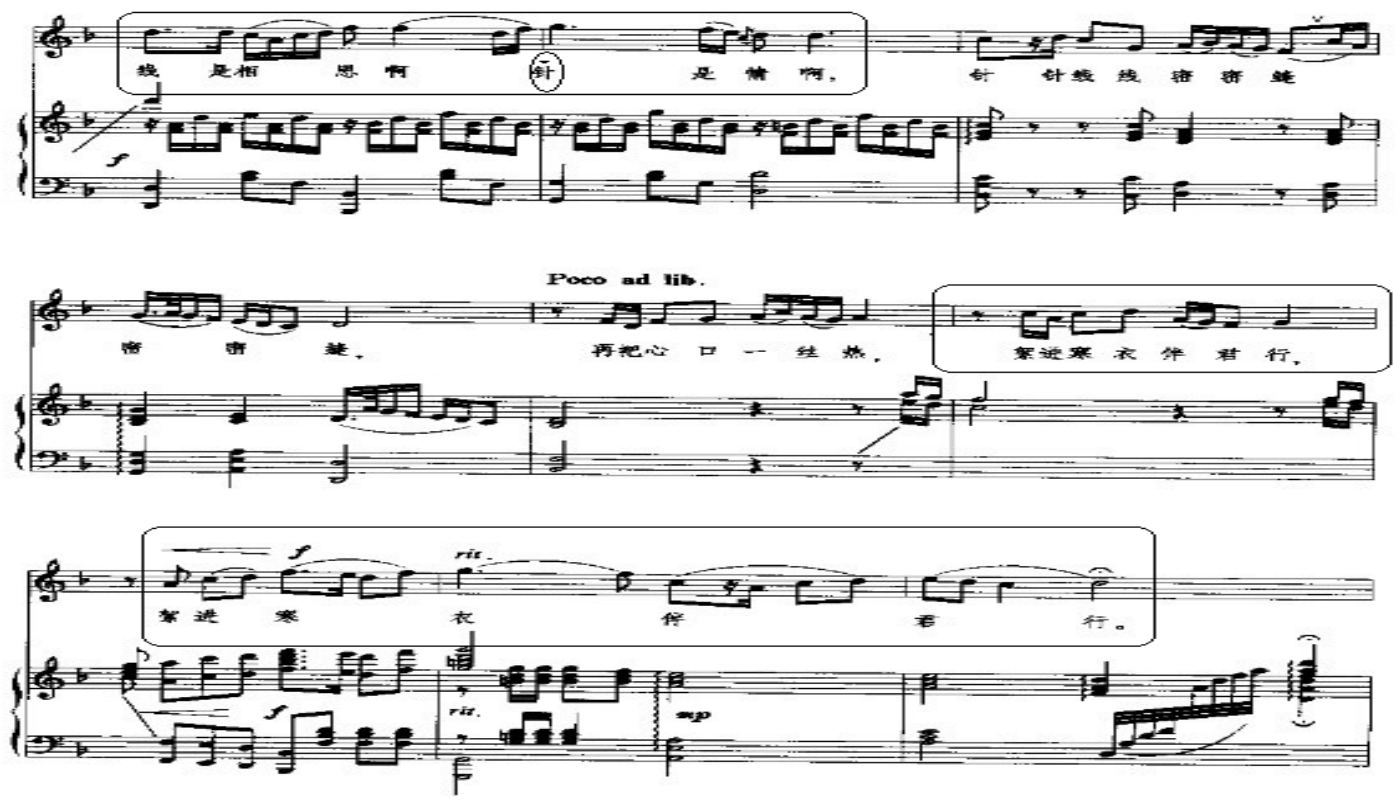
The fourth section is the climax of the whole song. The speed and tone change from slow to fast. The tonality changes to $\mathrm{Bb}$ mode. At same time, it adds the Yaoban element of traditional opera music. With tight playing and slow singing, and the extension of musical interval, it reflects Lady Meng Jiang's urge to send winter clothing to her husband. The artistic rendering is fully expressed.

Example 3
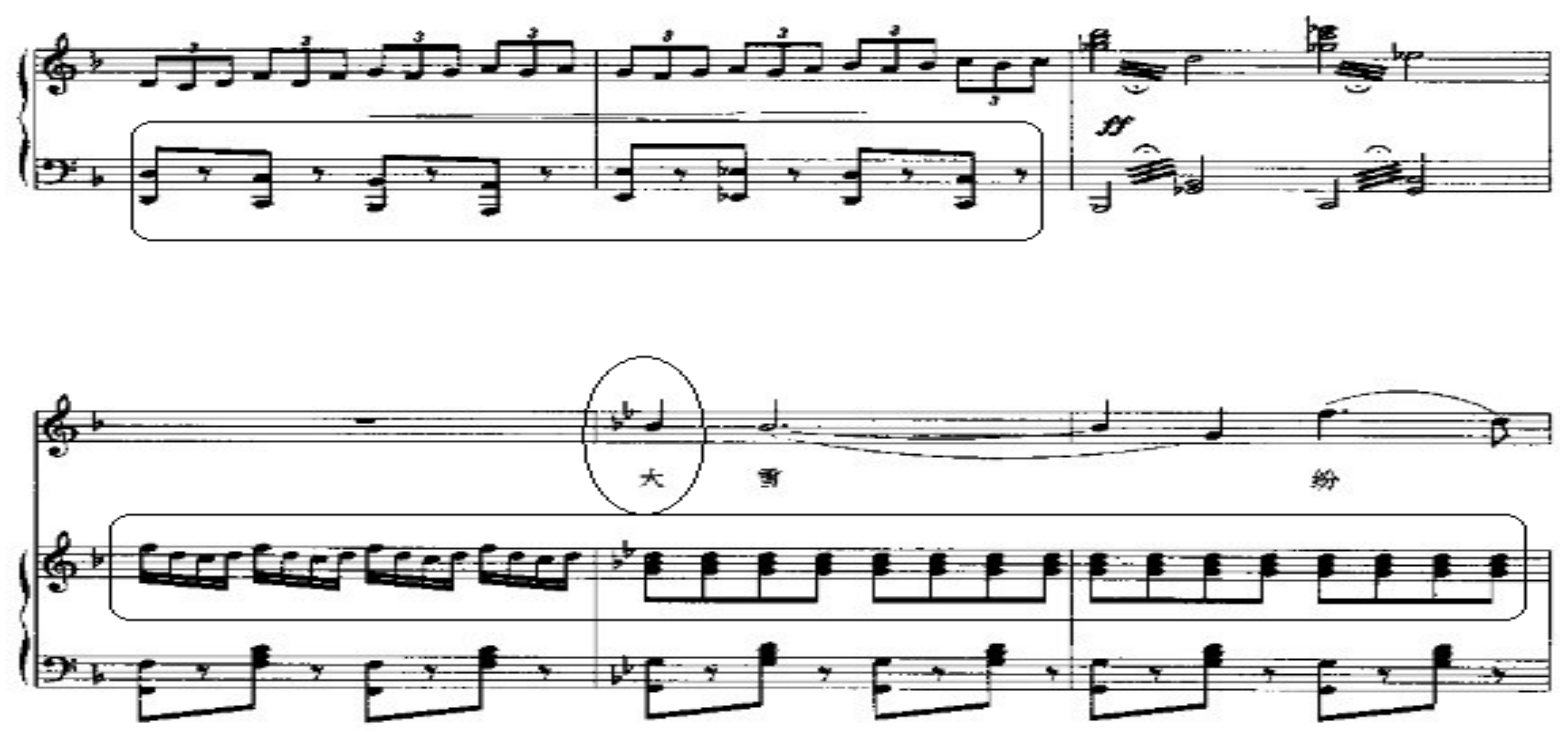

The interlude of four section changes the atmosphere of the entire music. The beat increases, and the atmosphere becomes intense. The melody changes from over sad to bold and unconstrained gradually. The continuous triplet reveals the inspiring emotion before the singing of singer. In the first sentence “大雪纷飞北风急, 孟姜女千里送寒衣”, the singer shall depict the bad weather with tense pace. The hardship in seeking her husband is a contrast to her love to her husband and clinging faith. The singing of every word shall be touching.
The rapid pace atmosphere brings the singer into the musical atmosphere. In the lyrics of “从秋走到年关过，年关过，不 知丈夫在哪里, 在哪里?”, “年关过” has more than sixteen beats, and “过” has eight beats. In singing, this eight beats shall be controlled with breath from strong to weak. And then it performs from weak to strong. Here, pay attention to breathing down, so that the tone will be fuller. It also can express Lady Meng Jiang's eagerness to find her husband.

\section{Example 4}
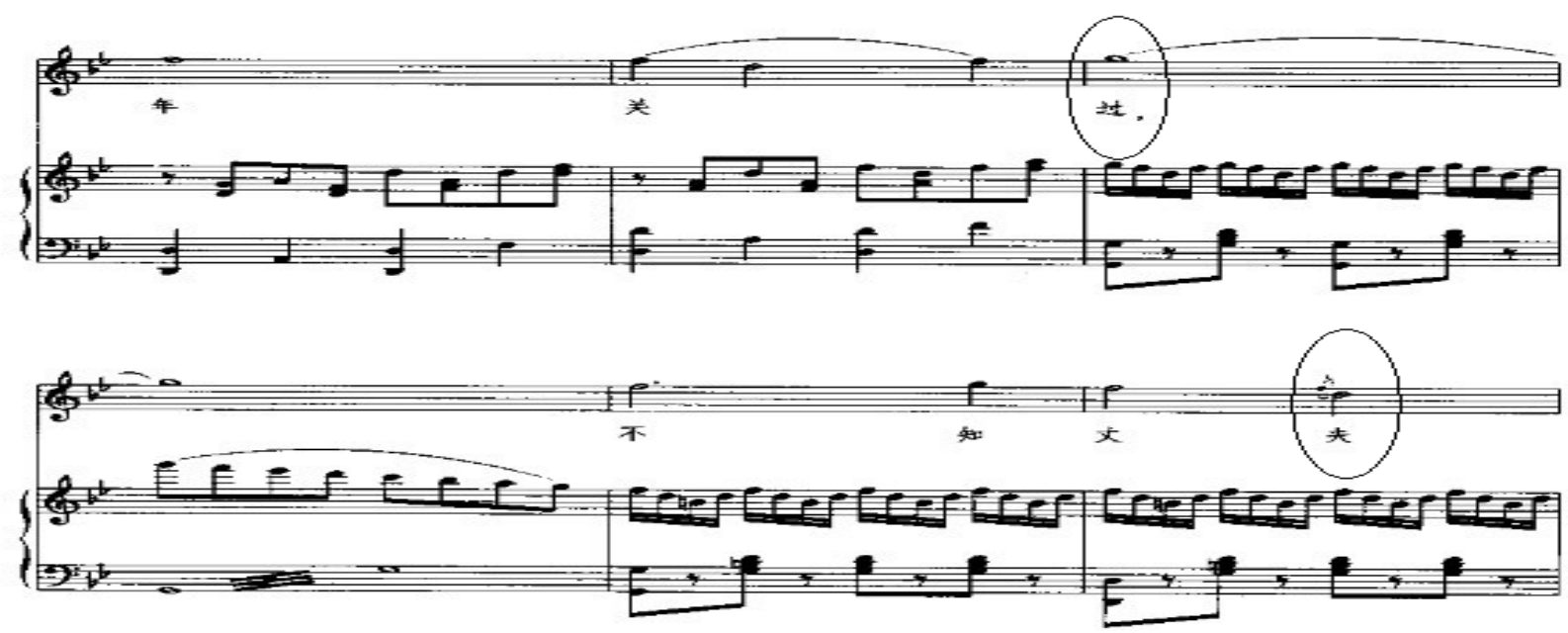

Next the singer can narrate plaintively to express the sadness of the heroine in wintry environment. The pace changes from fast to slow, and then slow to fast. All inner emotions are released in singing “哭倒长城八百里, 只见白
骨漫青山”. In repeat singing of “哭倒长城八百里, 只见白 骨漫青山”, use plaintive adagio and sing out with anger. The singer shall stress the initial sound and sing with a feeling of spout. “只见” uses the dotted note, so the singer shall pay 
attention to the support of breath, hold the voice and not stop breath, forming a feeling of “sob”. In processing “漫青山”, the singer shall pay attention to the high pitch timbre in singing “漫”, strengthen the voice and make up and down through, stabilize the breath supporting point, and sing with a painful and grieved feeling to express Lady Meng Jiang's extreme sadness. At the moment the music atmosphere reaches to the peak. Lady Meng Jiang took the bull by the horns to seek her husband thousands of miles away. Her angry cry seems to really collapse the Great Wall. The music vividly depicts this suffering ordinary woman under the feudal oppression, and her strong sadness.

Example 5

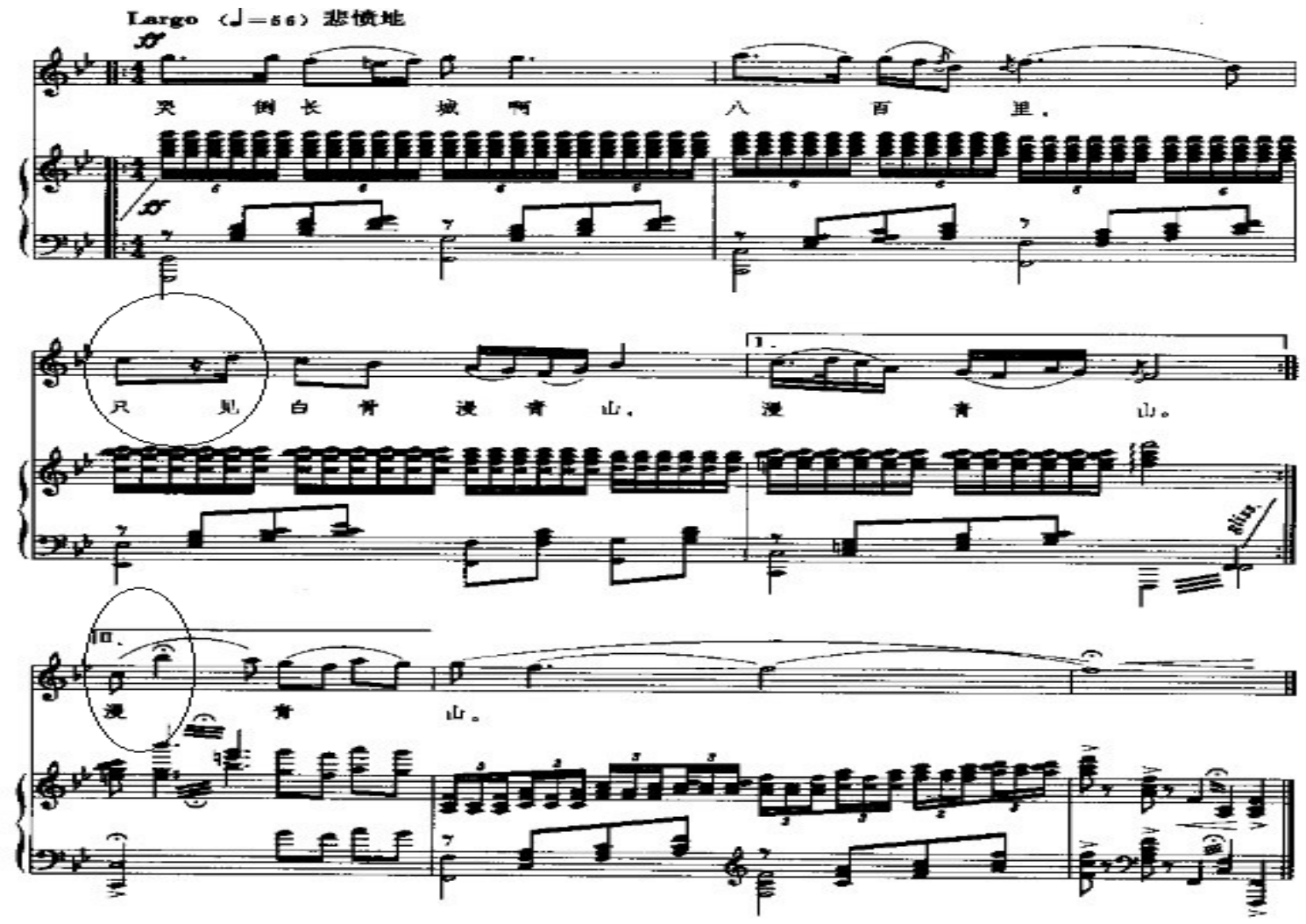

"Lady Meng Jiang" is a national vocal music works of Wang Zhixin. It is adapted according to a folk tale. The composer broke the traditional creation techniques and made bold innovation. He used opera elements and various other creation techniques, enriching expression content, music subjects and harmonic progression. His works have an important significance and extensive influence on national vocal music singing and teaching practice, and he has made a great contribution to the inheritance and development of folk music and local folk songs.

\section{REFERENCES}

[1] Liu Lin, Wang Zhixin. Mother River: Selection of Liu Lin \& Wang Zhixin's Vocal Works. Beijing: China Drama Press, 2002.

[2] Zhang Chou, Mao Kuangping. Anthology of Chinese Art Songs (II). Shanghai: Shanghai Education Press, 2007.

[3] Guo Xiangyi. Chinese National Vocal Music Textbook (Female I). Changchun: Jilin Audio \& Video Publishing House, 2000.

[4] Huo Li, Huo Ping, Li Jingyu. Newly-edited Chinese Vocal Works (5). Shenyang: Liaoning People's Publishing House, 2002. 